UNIVERSIDADE DE SÃO PAULO

ESCOLA DE ENGENHARIA DE SÃO CARLOS

DEPARTAMENTO DE TRANSPORTES

\title{
PROPOSTA DE UM MÉTODO DE ENSAIO PARA DETERMINAÇÃO DO VOLUME DE AZUL DE METILENO ADSORVIDO PELA FRAÇÃO FINA DE SOLOS TROPICAIS
}

Andréa de Oliveira Bonini

Orientador: Prof. Dr. Glauco Tulio Pessa Fabbri

Dissertação apresentada à Escola de Engenharia de São Carlos da Universidade de São Paulo para obtenção do título de Mestre em Engenharia Civil, Infra-Estrutura de Transportes.

São Carlos, novembro de 2005. 